\title{
LIVRO DIDÁTICO NOVAS PALAVRAS: UMA ANÁLISE DAS CONCEPÇÕES DE APRENDIZAGEM ${ }^{1}$
}

Amanda Canterle Bochett (UFSM)

Jéssica Cantele De Freitas (UFSM)

Maísa Helena Brum (UFSM)

Resumo: Diversas concepções de ensino e aprendizagem configuram o contexto público escolar brasileiro. Historicamente, muitos são os estudos sobre as teorias de aprendizagem, dos quais destacamos a teoria behaviorista, a cognitivista e a sociocultural. Com isso, busca-se identificar que concepções de aprendizagem subsidiam as atividades do livro didático Novas Palavras. Para tal, foram selecionados três capítulos do livro. Cada capítulo está organizado em três seções: Literatura Brasileira, Gramática e Redação e Leitura. Para a análise foram selecionados os primeiros capítulos de cada seção. O procedimento consistiu no levantamento de termos relacionados às concepções de aprendizagem desde a abertura do capítulo até as atividades. Os resultados indicam a predominância de atividades cognitivistas (39 ocorrências) nos três capítulos analisados. Em seguida, encontram-se as ocorrências de atividades socioculturais (8 atividades), que demonstram, principalmente na parte de redação e leitura, uma preocupação com a reflexão na produção dos textos propostos.

Palavras-chave: Concepções de aprendizagem; Livro didático; Atividades.

Abstract: Several teaching and learning conceptions shape the Brazilian
educational public context. Historically, there are many studies about
learning theories, of which we highlight the behaviorist, the cognitivist
and the sociocultural theories. Based on that, this article seeks to
identify which learning conceptions underline the pedagogical activities
from the Novas Palavras textbook. It was selected three chapters from
the textbook. Each chapter is organized according to three sections:
Brazilian Literature, Grammar, and Reading and Writing. For the analysis,
it was selected the first chapters of each section. The procedures
consisted in the mapping of terms related to the learning conceptions

1 Título do artigo em inglês: "NOVAS PALAVRAS TEXTBOOK: AN ANALYSIS OF THE LEARNING CONCEPTIONS" 
since the opening words of the chapter until its proposed activities. The results indicated the predominance of cognitivist activities (39 occurrences) in the three chapters analyzed. Following that, it was found some sociocultural activities (8 occurrences) that demonstrated, mainly in the Reading and Writing section, a concern towards the reflection in the production of the proposed texts.

Keywords: Learning conceptions; Textbook; Activities.

\section{INTRODUÇÃO}

Diversas concepções de ensino e aprendizagem configuram o contexto público escolar brasileiro. Historicamente, muitos são os estudos sobre as teorias de aprendizagem, dos quais destacamos a teoria behaviorista, a cognitivista e a sociocultural. Da mesma forma, as preocupações com o ensino e a aprendizagem dos alunos são temas discutidos há muito tempo por profissionais da área e que acabam levando a questionamentos como: qual(is) concepção(ões) devo/ preciso abordar em sala de aula? De que maneira? O que isto influencia no aluno?, entre tantos outros questionamentos. Essa preocupação dos professores com qual concepção se alinhar leva a perceber as relações entre pensamento, mente e linguagem no aprendizado.

Para o desenvolvimento desses fatores, é importante se pensar nas práticas pedagógicas diárias, pois são pautadas por concepções de aprendizagens particulares em instituições de ensino, e tem-se como questão fundamental a preocupação 
em desenvolver/utilizar materiais que correspondam à perspectiva que melhor desenvolva as competências dos alunos. Dessa forma, torna-se necessário compreender as concepções de aprendizagem e saber reconhecê-las em materiais didáticos, visando à realização de um trabalho que promova diferentes formas de construção do conhecimento, isto é, de pensar, refletir e agir em sociedade.

Para fins de análise, destacamos neste artigo três principais concepções de aprendizagem: a Behaviorista, que considera os estudos do comportamento e as condições ambientais (STAATS, 1980); a Cognitivista, que visa a salientar as descrições de regras e/ou estruturas que são comuns a todos (STETSENKO; ARIEVITCH, 2013); e a Sociocultural, que considera as interações com o meio social para a construção do processo de aprendizagem (LEGENDRE, 2010). Em outras palavras, será estudado em que medida essas concepções subsidiam as atividades do livro didático Novas Palavras, cujos autores são Emília Amaral, Mauro Ferreira, Ricardo Leite e Severino Antônio, e publicado pela Editora FTD S.A., em 2013.

O objetivo deste trabalho é identificar as concepções de aprendizagem que subsidiam as atividades do livro didático em pauta, tendo em vista a sua disponibilidade em uma 
Instituição Federal de Ensino Básico Técnico e Tecnológico, no estado do Rio Grande do Sul. A pesquisa consiste na identificação, por meio de análise, das concepções presentes nas atividades propostas em três capítulos do livro, que dão conta da apresentação de conteúdos e exercícios, considerando o primeiro capítulo de cada uma das seções apresentadas (Literatura Brasileira, Gramática e Redação e Leitura).

Com este trabalho pretende-se contribuir com os estudos de materiais didáticos e proporcionar uma reflexão que subsidie a prática pedagógica de professores em relação a concepções de aprendizagem aplicadas em sala de aula.

\section{REFERENCIAL TEÓRICO}

Para a realização da pesquisa, será apresentado um levantamento das três concepções de aprendizagem buscadas nas unidades analisadas, no que concerne a suas definições e características.

\section{A CONCEPÇÃO DE APRENDIZAGEM BEHAVIORISTA}

A teoria behaviorista surgiu para romper com o paradigma vigente na psicologia da época, que tinha a introspecção como método. Acreditava-se, até então, que a tarefa da Psicologia era estudar a estrutura e o funcionamento da mente humana, com a atenção voltada aos aspectos internos, 
como as percepções, os sentimentos e a personalidade do homem, pois se considerava que o comportamento humano era determinado pelos pensamentos.

Nesse sentido, o behaviorismo se instaurou para fazer uma revolução no campo da psicologia (STAATS, 1980), excluindo a ideia de que tudo vem de dentro e substituindo o foco nos processos internos pelo estudo do comportamento humano.

Seu programa era o do estudo do comportamento, das condições ambientais e dos princípios dos quais o comportamento era uma função. Isto, considera-se, representa um behaviorismo básico. Ainda que esse programa tenha sido uma correção para os abusos da época, ele foi, entretanto, radical e por isto mesmo rejeitou importantes áreas de estudo, estendendo esta rejeição aos termos e métodos da introspecção. (STAATS, 1980, p.100)

Essa ciência do comportamento substituiu a análise do subjetivo pela análise do "por que fazemos o que fazemos e o que devemos e não devemos fazer" (Baum, 1999, Apud TERRA, 2003, s/p). O behaviorismo passou por três gerações distintas, brevemente apresentadas a seguir.

A primeira geração, denominada Behaviorismo Metodológico, foi inaugurada por John B. Watson, em 1913, sendo postulado o comportamento como objeto de estudo. Esse movimento tomou como base o realismo, que defendia a 
ideia de existência de um mundo real externo, a partir do qual se constituía o mundo interno. Watson compreendia que o homem possui um aparato orgânico que se adapta ao ambiente em que vive; nesse sentido, defendia que "o comportamento deve ser estudado como função de certas variáveis do meio, sob o argumento de que certos estímulos levam o organismo a dar determinadas respostas" (TERRA, 2003, s/p).

O behaviorismo dessa geração era fundamentado na lei do condicionamento clássico de Pavlov, pelo qual as respostas se davam por estímulos do ambiente. Dessa maneira, Watson instaurou o conceito de reflexo condicionado, que tratava de interações em estímulo-resposta, sofridas pelo sujeito através do ambiente, fazendo com que o indivíduo passasse a responder por estímulos a que antes não respondia.

A segunda geração denominava-se Behaviorismo Radical, introduzida por Skinner, e defendia a análise experimental do comportamento. Eram adotados princípios do pragmatismo, defendendo que a grande realização da ciência estava no fato dela permitir "dar significado a nossa experiência" (TERRA, 2003, s/p). Deixou de ser pautada em métodos para adotar conceitos e termos, passando a admitir todos os eventos naturais passíveis de serem acessados e excluindo os eventos fictícios, como a mente e todas as suas partes e processos. 
Surge a concepção de comportamento operante, pelo qual a aprendizagem deixa de ser um condicionamento, e passa a se considerar a interação sujeito e ambiente, ocorrendo um estímulo denominado reforço, o qual assume a responsabilidade pela ação. A aprendizagem está, nesse sentido, na relação entre uma ação e o seu efeito (TERRA, 2003, s/p).

A terceira geração, denominada Behaviorismo Social, representada por Staats, passou a reconhecer que a análise do comportamento deve considerar os processos simbólicos, concentrando o interesse na análise do pensamento e dos mecanismos que ele utiliza para controlar a ação. Além disso, colocou em pauta a ênfase nos processos autorregulatórios, pelos quais a própria pessoa é capaz de organizar seu condicionamento, e trouxe a ideia de aprendizagem através de modelação, pela qual a aquisição de conhecimentos e comportamentos novos se dá por meio de observação (TERRA, 2003, s/p).

No que concerne ao papel da aprendizagem no desenvolvimento, pode-se considerar que ela veio à tona como a ascensão do behaviorismo, visto que essa teoria tentou especificar os mecanismos de aprendizagem que sustentaram as mudanças no comportamento. Entretanto,

as teorias behavioristas foram fundamentadas em pesquisas sobre como os animais 
aprendem a realizar comportamentos. Aprendizagem das crianças, particularmente na escola, não era o foco direto. Embora algumas inferências tenham sido retiradas de estudos em animais sobre o ensino e educação de crianças, esta abordagem não poderia e não oferece muita reflexão sobre como o ensino-aprendizagem afeta o desenvolvimento da mente. (STETSENKO; ARIEVITICH, 2013, p.2)

O que se compreende sobre a concepção behaviorista de aprendizagem dos alunos se dá por meio de inferências realizadas a partir do estudo do comportamento observado em animais. Ainda, o behaviorismo considerava, em primeiro plano, os estudos do comportamento e as condições ambientais dos sujeitos (STAATS, 1980), isto é, acreditava-se que qualquer produção humana, inclusive a linguagem, era resultado de uma sucessão de hábitos adquiridos por meio de um condicionamento operante e, portanto, desconectados de qualquer processamento cognitivo (TICKS, 2008).

\section{A CONCEPÇÃO DE APRENDIZAGEM COGNITIVISTA}

A ascensão do cognitivismo se deu em meados da década de 1970, quando a influência behaviorista entrou em declínio. Com a teoria que surgia, a aprendizagem em si deixou de atrair a atenção, sendo substituída pelo interesse no estudo das leis universais da "máquina mental" 
(STETSENKO; ARIEVITCH, 2013). Nessa perspectiva, a teoria cognitivista destina-se a apontar a descrição de regras e estruturas comuns a todos os seres humanos, independente do contexto.

Por exemplo, a partir de uma posição cognitivista, o que importa na análise da memória humana não é como as crianças aprendem a memorizar certos tipos de material, nem como sua aprendizagem depende das maneiras que elas são ensinadas. Tudo o que importa são as características de uma capacidade de armazenamento geral predeterminada e praticamente imutável, que é pensada para ser melhor revelada através de pesquisas sobre a memorização de informações sem sentido (por exemplo sequências de letras ou números) em experiências escolares ou quaisquer outras práticas de aprendizagem em que a criança está envolvida. (STETSENKO; ARIEVITCH, 2013, p.2)

Nessa teoria, o progresso dos alunos no desenvolvimento de capacidades mentais é atribuído às suas próprias experiências e descobertas independentes. A teoria não tem como foco verificar se aquilo que é ensinado aos discentes afeta ou não e de que maneira pode afetar o seu desenvolvimento cognitivo, verificando-se, assim, que o papel de ensino-aprendizagem no desenvolvimento mental é ignorado nessa perspectiva (STETSENKO; ARIEVITCH, 2013, p.3). 
Nesse sentido, essa perspectiva dá ao aluno lugar central na construção de seus próprios saberes, de modo que o professor não ocupa papel de destaque nessa concepção.

Um grande nome de influência da teoria cognitivista é Jean Piaget, psicólogo, epistemólogo e biólogo de formação que se voltou para o estudo do conhecimento, objetivando oferecer uma explicação biológica das formas do conhecimento. Sua perspectiva epistemológica se preocupa em compreender "como os conhecimentos aumentam e por que processos eles passam de um nível de complexidade para outro", sendo o conhecimento considerado como um processo de adaptação que está em constante mudança (LEGENDRE, 2010, p.430).

Dentre as contribuições de Piaget está a concepção de estruturas de conhecimentos pelos quais são organizados os dados da experiência humana. Essas estruturas não são inatas, elas estão em evolução e abertas para novas evoluções. Além disso, Piaget reconhece o papel ativo do pensamento na estrutura da experiência, de modo que as estruturas do conhecimento são compreendidas como um processo dinâmico e evolutivo, o que faz surgir a ideia de que o sujeito constrói ativamente os seus conhecimentos muito mais do que recebe do exterior de forma passiva (LEGENDRE, 2010). 
O conhecimento, segundo essa concepção, era construído por meio da interação do sujeito com um ambiente propício à sua aprendizagem, no que tange à maturação biológica para compreender um dado conhecimento (PIAGET, 1983). Em outras palavras, o cognitivismo focalizava as descrições de regras e/ou estruturas que são comuns a todos (STETSENKO; ARIEVITCH, 2013), independente do contexto em evidência.

No que se refere à pedagogia, Piaget considera que ensinar não se limita a transmitir conhecimentos e a aprendizagem não é apenas memorização de verdades já elaboradas. "Piaget insiste nos limites da pedagogia da transmissão, que privilegia essencialmente o discurso em detrimento da atividade do sujeito discente, e põe em evidência o papel central do aluno na elaboração dos seus próprios conhecimentos" (LEGENDRE, 2010, p.440), o que reforça a ideia de que o aluno tem o papel central em suas aprendizagens.

Na concepção de Piaget, a aprendizagem é uma atividade de procura de sentido e ela só pode ser significativa para o aluno na medida em que traz algum fundamento para ele.

O mestre deverá estimular o aluno a explicar o seu raciocínio, levando-o a justificar as suas respostas por meio de argumentos, organizar contra-exemplos a fim de estimular a sua reflexão, evidenciar contradições 
ou incoerências e ajudá-lo a superá-las, dando-lhe acesso aos recursos necessários. É principalmente pela experimentação, pela discussão, pela troca de pontos de vista e pelo choque das ideias que o aluno será levado a tomar consciência daquilo que sabe, mas também dos limites dos seus conhecimentos anteriores e da pertinência de integrar novos saberes. (LEGENDRE, 2010, p.442)

Dessa maneira, o aluno possui papel central no seu processo de aprendizagem, entretanto, para que esse processo se concretize, é necessário que o docente guie o aluno para reconstruir noções, dando a ele oportunidade de experimentar ativamente e buscar soluções para os problemas que enfrenta (LEGENDRE, 2010, p.442).

\section{A CONCEPÇÃO SOCIOCULTURAL DE APRENDIZAGEM}

A perspectiva sociocultural, concebida por Lev Semenovick Vygotsky (1896-1934), trouxe para a área da Psicologia e, consequentemente, para a área da Linguística e da Educação, uma nova visão sobre o desenvolvimento da linguagem e a construção do conhecimento nos indivíduos. Essa nova visão buscou se afastar de concepções anteriores sobre o desenvolvimento da mente humana, como as concepções behaviorista e cognitivista do desenvolvimento.

Essa concepção

postula que as mentes das crianças desenvolvem-se como resultado de 
interações constantes com o mundo social o mundo das pessoas que fazem coisas com e para o outro, que aprendem uns com os outros e usam as experiências de gerações anteriores para enfrentar com sucesso as exigências da vida no presente. (STETSENKO; ARIEVITCH, 2013, p.4)

Dessa maneira, é através das relações com o meio social que se dará o processo de aprendizagem. Nessa abordagem, o papel do professor é de grande importância, no sentido de que a aquisição do conhecimento não pode ser separada de um processo coletivo de elaboração de sentidos. A construção de significações por parte do aluno se dá de forma socialmente compartilhada, entre bases culturais comuns (LEGENDRE, 2010).

Vygotsky tinha como interesse compreender a gênese da cultura e, dessa maneira, compreender as funções psíquicas superiores próprias aos humanos (LEGENDRE, 2010). Nesse sentido, Vygotsky situa a origem da consciência no mundo social, de forma que

pensamento e consciência não constituem características puramente internas, pois são elaborados a partir de atividades externas e objetivas, realizando-se em um ambiente social determinado. Eles procedem da atividade humana, que representa para Vygotsky o princípio explicativo fundamental. A noção de atividade, considerada como 
a unidade de análise da psicologia, integra as dimensões ao mesmo tempo social e individual, interativa e cognitiva, das condutas. (LEGENDRE, 2010, p.451)

Desse modo, a atividade não é apenas uma adaptação ao meio, e sim uma transformação do meio pelo ser humano, o que faz com que ele transforme a si mesmo. A atividade se cumpre pela mediação de instrumentos, surgindo, assim, a concepção de instrumento-e-resultado de Vygotsky, que considera que nem todas as necessidades do ser humano podem ser realizadas através do uso de instrumentos que já existem na sociedade: "frequentemente, precisamos criar um instrumento que é especificamente projetado para criar o que afinal desejamos produzir" (NEWMAN; HOLZMAN, 1993, p.51).

Essa constatação representa a necessidade de se criarem ferramentas para auxiliar o processo de aprendizagem do aluno que sejam apropriadas à situação específica. Os instrumentos da "loja de ferramentas", prontos para o uso coletivo da sociedade, nem sempre são eficientes para determinados propósitos; é necessário o uso de "ferramentas do ferramenteiro" em muitos momentos, aquelas que são criadas exclusivamente para atingir um determinado objetivo. 
A ideia de Vygotsky sobre o instrumento do ferramenteiro considera que este é "criado com o fim de ajudar a criar um produto específico, ele não tem qualquer identidade social pré-fabricada independente dessa atividade" (NEWMAN; HOLZMAN, 1993, p.52). Assim, os alunos realizam o processo de aprendizagem em um meio social através de ferramentas adequadas ao seu contexto e apropriadas às suas necessidades no momento.

$\mathrm{Na}$ abordagem sociocultural, considera-se que todo o conhecimento é situado, não podendo dissociar-se da cultura em que está inserido, nem das ferramentas a que ele recorre.

Nessa perspectiva, a aprendizagem caminha ao lado da imersão da pessoa na cultura e não poderia, consequentemente, constituir uma trajetória puramente individual. Isso não minimiza o papel do discente, pois, para elaborar uma compreensão comum, é preciso compreender ao mesmo tempo o seu próprio pensamento e o pensamento dos outros, é preciso conseguir tomar como objeto de reflexão o próprio conteúdo do seu pensamento (LEGENDRE, 2010, p.462)

As interações sociais possuem papel de grande importância no processo de aprendizagem. Além disso, o professor exerce grande influência nesse processo, no sentido de que deve ser capaz de disponibilizar ferramentas adequadas para 
o contexto de ensino. Na elaboração dos saberes, o papel do discente possui importância pelo fato de que é necessário realizar uma reflexão do que está sendo proposto para que seja capaz de construir o conhecimento.

Em contraponto com as perspectivas anteriores, a sociocultural, como o próprio nome evidencia, busca evidenciar o papel das interações com o meio social para a construção do processo de aprendizagem (LEGENDRE, 2010). A perspectiva sociocultural considera que o indivíduo não pode ser abstraído do seu contexto histórico e cultural, pois ele transforma o contexto no qual está inserido e é transformado por este.

\section{METODOLOGIA}

\section{Universo de análise}

Para a realização da análise pretendida, apresenta-se como universo de análise um livro didático aprovado pela avaliação do Programa Nacional do Livro Didático para o Ensino Médio (PNLD), intitulado Novas Palavras - 3 volumes, tendo em foco o 3 o volume.

O livro em questão refere-se à edição para alunos, que apresenta, em sua constituição, três seções principais que fundamentam sua divisão: Literatura Brasileira, Gramática e Redação e Leitura. 
Para a análise foi escolhido o primeiro capítulo de cada uma das três seções supracitadas. O primeiro capítulo da seção de Literatura Brasileira é composto de textos iniciais com a temática Pré-Modernismo no Brasil, seguido de atividades de releitura. O primeiro capítulo da seção de Gramática é composto por conceitos sobre orações subordinadas, seguido de atividades. E, por fim, o primeiro capítulo da terceira seção, referente à Redação e Leitura, apresenta textos modelo e exemplos para depois solicitar, por meio de propostas, a produção textual.

\section{Procedimentos de análise}

A análise compreende procedimentos de cunho quantitativo e qualitativo, respectivamente. Para a análise das concepções de aprendizagem foram seguidas as etapas: (1) identificação das concepções de aprendizagem que subsidiam cada uma das atividades nos três capítulos analisados; (2) recorrência do número de atividades referentes a cada uma das concepções apresentadas; (3) análise e exemplificação dessas atividades em busca de evidências léxico-gramaticais das teorias de aprendizagem discutidas no Capítulo 2.

\section{RESULTADOS E DISCUSSÃO}

Nesta análise, constatou-se a predominância da concepção cognitivista (39 ocorrências), tanto em orientações 
de estudo quanto nas atividades propostas, e a minoria das atividades como subsidiadas pela perspectiva sociocultural (08 ocorrências). Não foram encontradas ocorrências da perspectiva behaviorista. O Gráfico 01 demonstra as ocorrências encontradas:

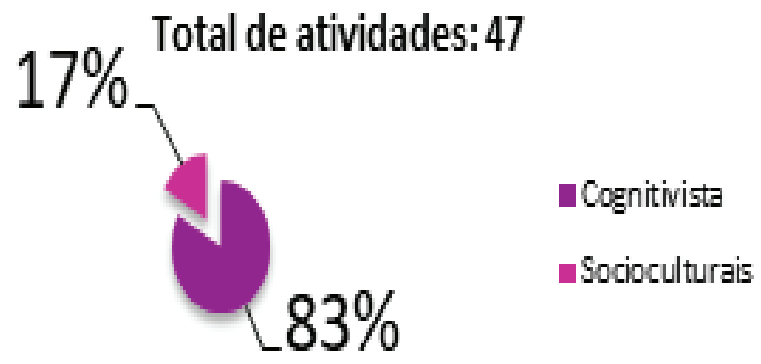

Gráfico 01- Total de atividades

É nas atividades cognitivistas que se expressa a construção do aluno em relação aos seus próprios conceitos, em estruturas que visam as descrições, pois o professor não é peça fundamental para a construção desses conceitos, de acordo com Stetsenko e Arievitch (2013). Dessa forma, as análises tiveram o foco nas atividades propostas.

Tendo em vista o modo de organização estrutural do livro didático adotado, dividido em três seções, a seguir será discorrido sobre cada uma das seções e a sequência de cada capítulo inicial. 


\section{PRIMEIRA SEÇÃO: “LITERATURA BRASILEIRA”}

O primeiro capítulo da seção do livro intitulada "Literatura Brasileira" apresenta um texto inicial sobre a inauguração do Teatro Municipal de São Paulo, no capítulo do Prémodernismo. A seguir, uma seção intitulada "Releitura" retoma assuntos desse texto com a busca de informações e escolas literárias estudadas anteriormente, revendo, assim, outros conteúdos que não são o foco do capítulo. A Figura 01 mostra a organização retórica da seção:

\section{SEÇÃO: UTERATURA BRASILEIRA "PRÉ-MODERNISMO NO BRASIL"}

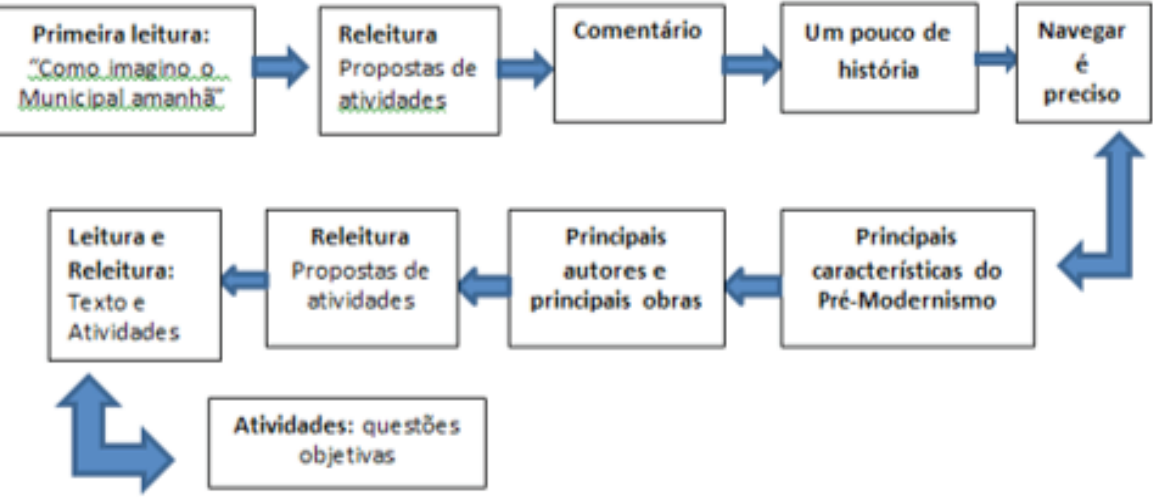

Figura 01 - Organização retórica da seção de "Literatura Brasileira"

$\mathrm{Na}$ parte de "Releitura" são propostas atividades referentes aos fragmentos de obras expostos. Reforça-se, assim, a predominância da construção de conhecimentos 
dentro de uma concepção cognitivista que, de acordo com Piaget (1995), se dá na ativação e no contato com informações, no caso dentro do texto. A seguir, pode ser observado um exemplo de atividade cognitivista:

\begin{tabular}{|l|l|l|}
\hline 01 & $\begin{array}{l}\text { No texto 01, a que atitude o autor se refere repetidamen- } \\
\text { te para simbolizar a apatia de Jeca- Tatu? }\end{array}$ & Cognitivista \\
\hline
\end{tabular}

O exemplo 01 demonstra a relação de construção de uma resposta a partir de conceitos que simbolizam "atitudes", localização de informação específica no texto como estratégia de leitura, sendo justificada sua classificação pelo que Piaget (1995) afirma em relação à aprendizagem ser uma busca de sentido pelo aluno. Essas questões que exploram o desenvolvimento de habilidades cognitivas chegam a $83 \%$, sendo outras $17 \%$ socioculturais, como demonstra o gráfico a seguir:

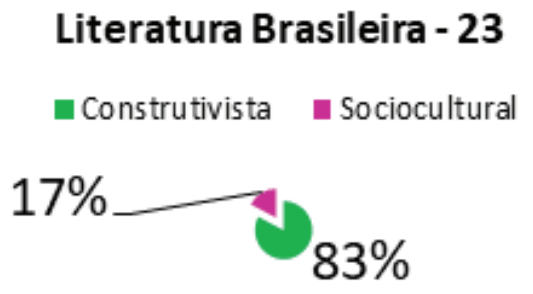

Gráfico 02 - Atividades de Literatura Brasileira

A seção demonstra também a inclusão de uma proposta de debate e um resumo de todos os conceitos tratados na unidade, e é neste momento que se inserem as atividades 
socioculturais, reforçando a noção de Stetsenko e Arievitch (2013) em relação à aquisição de conhecimentos não ser separada do coletivo e da construção de sentidos. Essa proposta pode ser observada no exemplo 02:

\begin{tabular}{|l|l|l|}
\hline 02 & $\begin{array}{c}\text { Debate interdisciplinar - a atualidade do problema dos } \\
\text { dois "Brasis" }\end{array}$ & Sociocultural \\
$\begin{array}{l}\text { Discuta com seus colegas em que medida o problema de } \\
\text { contradição entre desenvolvimento e atraso, historica- } \\
\text { mente existente em nosso país, mantém-se atual... }\end{array}$ & \\
\hline
\end{tabular}

Assim, o exemplo 02 demonstra a relação de conhecimentos coletivos e elaboração de novos, com a construção de significações de forma socializada, no que se refere a um problema histórico persistente até os dias de hoje. Da mesma forma, apresentam-se na sequência questões objetivas relacionadas aos conceitos abordados nos textos, voltando às relações cognitivistas já expostas.

\section{SEGUNDA SEÇÃO: "GRAMÁTICA"}

No primeiro capítulo da segunda seção do livro didático, que trata de "Gramática", é apresentada uma introdução sobre períodos compostos. A Figura 02 mostra como a seção de gramática está organizada: 
2 SEÇÃO: GRAMÁTICA “PERÍODO COMPOSTO POR SUBORDINAÇÃO”
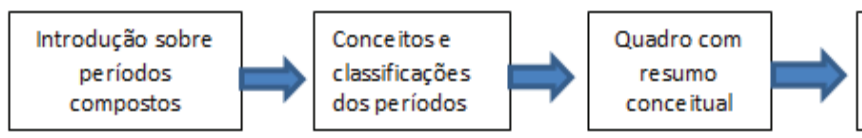

Atividades

07 questões

Figura 02 - Organização retórica da seção de "Gramática"

Todas as 10 propostas de atividades, de acordo com as concepções de aprendizagem, corresponderam a ocorrências de caráter cognitivo, como pode ser visualizado no Gráfico 03:

\section{Gramática}

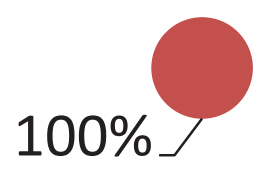

- Cognitivista

Gráfico 03 - Total de atividades da seção "Gramática"

As atividades cognitivas, aqui, dizem respeito a classificações gramaticais baseadas em conceitos apresentados anteriormente, reforçando o pensamento do aluno como papel central de seu aprendizado. Outras ressaltam a identificação de elementos em períodos dados e outras ainda são objetivas apenas no sentido de cobrar 
conceitos, demonstrando o professor como guia para que o aluno consiga construir suas noções e saiba identificá-las, como pode ser visto no exemplo 03:

\begin{tabular}{|l|l|l|}
\hline 03 & $\begin{array}{l}\text { Nas frases a seguir, substituindo o termo destacado por } \\
\text { uma oração substantiva de mesma função sintática e de } \\
\text { sentido equivalente, transforme o período simples em } \\
\text { um período composto. Depois classifique a nova oração. }\end{array}$ & Cognitista \\
\hline
\end{tabular}

Neste exemplo, nota-se que a proposta é apenas de cunho conceitual/ classificatório, reproduzir algo que já foi estudado em outro momento. Dessa forma, reforça a afirmação de Legendre (2010) no que se refere ao aluno tomar consciência daquilo que sabe, constituindo-se na maior parte das atividades da seção de gramática.

\section{TERCEIRA SEÇÃO: "REDAÇÃO E LEITURA"}

A terceira e última seção do livro trata de "Redação e Leitura", que enfatiza aspectos referentes ao texto, como se a gramática fosse algo separado da produção textual. A organização do primeiro capítulo da seção pode ser visualizada na Figura 03: 


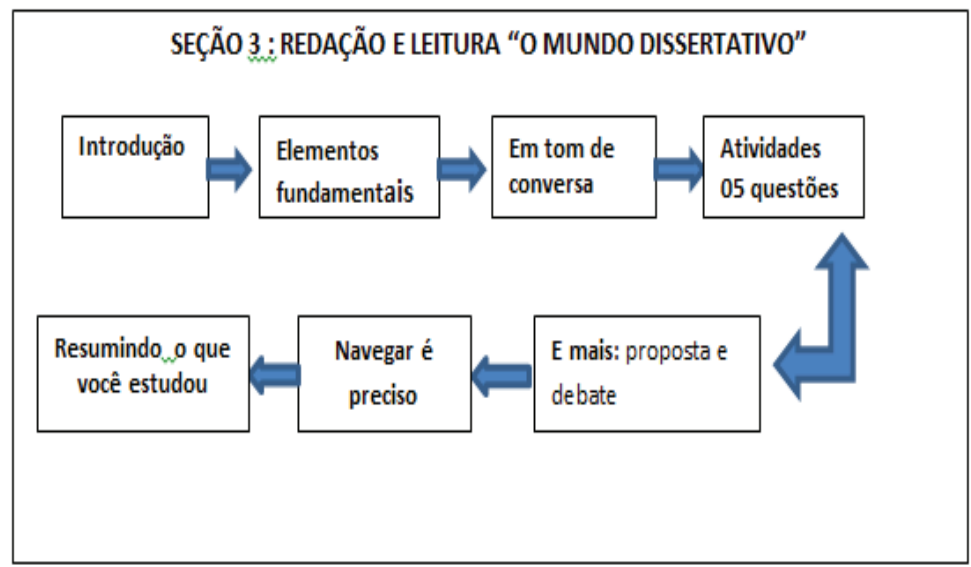

Figura 03 - Organização retórica da seção de "Redação e Leitura"

As atividades são propostas após uma introdução - "O mundo dissertativo" - e exposição de elementos fundamentais sobre redação. Nessa seção, as ocorrências de concepções de aprendizagem podem ser vistas a partir do Gráfico 04:

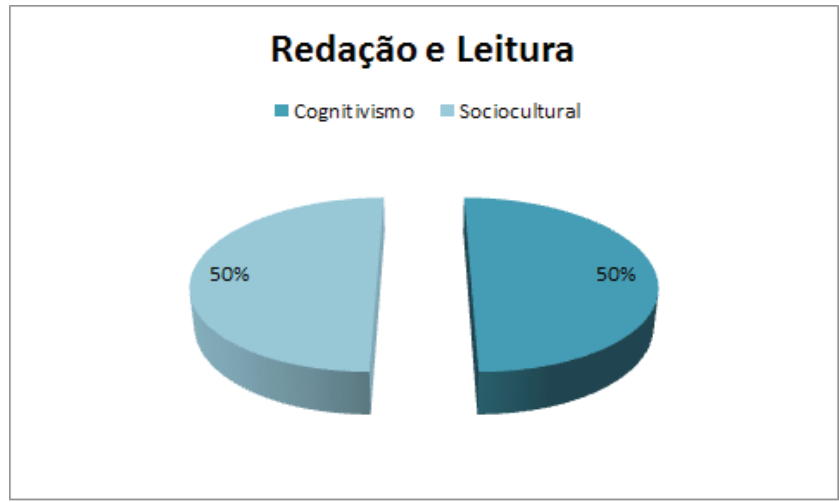

Gráfico 04 - Total de atividades da seção: "Redação e Leitura" 
Nessa seção, as propostas de atividades são realizadas na mesma proporção, 03 ocorrências de atividades cognitivistas e 03 ocorrências socioculturais. Como nas seções apresentadas anteriormente, não foram encontradas ocorrências behavioristas. As atividades cognitivistas podem ser justificadas pelas concepções de Piaget (1995) no que concerne à busca de sentidos. Uma proposta cognitivista pode ser vista no Exemplo 05.

\begin{tabular}{|l|l|l|}
\hline 05 & $\begin{array}{l}\text { Leia cuidadosamente os textos a seguir. Depois identifi- } \\
\text { que, em cada um deles, o tema, o ponto de vista e os ar- } \\
\text { gumentos principais. }\end{array}$ & Cognitivista \\
\hline
\end{tabular}

Esse exemplo demonstra a habilidade cognitiva explorada ao solicitar a identificação de pontos de vista e argumentos, ou seja, não é uma elaboração. A identificação de elementos retoma a questão de o aluno ter o papel central e tomar ciência de seus conhecimentos ao responder às propostas. A parte cognitivista na seção corresponde a uma separação clara entre gramática e texto, como se fossem aspectos independentes.

As ocorrências que procuram fazer o aluno ler criticamente o tema discutido estão dispostas com mais propriedade nas outras seções, demonstrando a perspectiva de Vygotsky (2001) na elaboração de ferramentas que auxiliem no desenvolvimento do aluno, tendo em vista a noção de "instrumento para resultado". Pode-se observar o exemplo 06 como ocorrência sociocultural. 


\begin{tabular}{|l|l|l|}
\hline 06 & $\begin{array}{l}\text { Produza um parágrafo expositivo sobre como você viven- } \\
\text { cia o natal. Em seguida, crie um parágrafo argumentati- } \\
\text { vo, defendendo seu ponto de vista sobre essa data. }\end{array}$ & Sociocultural \\
\hline
\end{tabular}

O exemplo acima demonstra ser uma ocorrência de proposta sociocultural ao retomar que todo conceito é situado e leva em consideração a cultura dos alunos. Dessa forma, ao ser proposto um parágrafo expositivo sobre a vivência particular do aluno na data comemorativa de Natal, compreende-se que as questões sociais e culturais terão influência em seu desenvolvimento intelectual. Em tese, a concepção sociocultural subjacente às propostas, embora ainda poucas no âmbito geral, trazem a reflexão como ponto importante e, mais ainda, como influência no processo social de construção de saberes.

Nesse sentido, demonstra-se, por meio desta análise, a importância da compreensão e reflexão sobre as práticas diárias do professor em relação às concepções de aprendizagem, principalmente no uso de material didático.

\section{CONSIDERAÇÕES FINAIS}

A reflexão sobre aprendizagem é importante em todos os níveis de ensino, principalmente quando se refere à preocupação com uma boa prática pedagógica. Dessa forma, a necessidade de analisar materiais didáticos está relacionada ao entendimento das concepções de aprendizagem e de como elas subsidiam tal produção. 
O livro didático em estudo chamou atenção no que se refere às atividades propostas. As análises demonstram que em Novas Palavras predomina a concepção de aprendizagem cognitivista, de Piaget (1995), que induz a construção de conceitos. Já em menor recorrência, as atividades que focalizam a reflexão acerca de práticas sociais, de Vygostky (2001), ainda que tímidas, procuram tornar o aluno mais reflexivo e interativo. Pode-se compreender que todas as concepções de ensino referidas possuem importância na construção da aprendizagem dos alunos, cada uma com diferentes maneiras de explorar esse desenvolvimento. Porém, consideramos que a mais desejável para o desenvolvimento do aluno como crítico e reflexivo seja a perspectiva sociocultural.

Ressalta-se, por fim, a importância da análise de materiais didáticos para a compreensão e aplicação das concepções de aprendizagem mais adequadas ao desenvolvimento dos alunos em sala de aula, de acordo com os objetivos pretendidos.

\section{REFERÊNCIAS}

AMARAL, Emília; PATROCínIO, Mauro Ferreira do; LEITE, Ricardo Silva; BARBOSA, Severino Antônio Moreira (2013). Novas Palavras: 3o ano. 2ed. São Paulo: FTD.

LEGENDRE, Marie-Françoise(2010a). "LevVygotskye o socioconstrutivismo na educação". In: GAUTHIER, Clermont; TARDIF, Maurice. A pedagogia: teorias e práticas da antiguidade aos nossos dias. Petrópolis, RJ: Vozes. 
NEWMAN, Fred; HOLZMAN, Lois (1993). Lev Vygotsky: cientista revolucionário. Tradução de Marcos Bagno. São Paulo: Editora Loyola. PIAGET, Jean (1983). A epistemologia genética: sabedoria e ilusões da filosofia; problemas de psicologia genética. 2.ed. São Paulo: Abril Cultural. Coleção Os pensadores.

(1985). The construction of reality in the child. Margaret Cook (Trad.). Routledgeand Kegan Paul. In http://marxists.org/reference/ subject/philosophy/works/fr/piaget2.htm. Acesso em 6.Mai.2018.

STAATS, Arthur W (1980). "Behaviorismo social: uma ciência do homem com liberdade e dignidade". Arquivos Brasileiros de Psicologia. 32(4), 97116.

STETSENKO, Anna \& ARIEVITCHL, Igor. (2013). Teaching, learning and development: a post-vygotskian perspective. In https://pdfs. semanticscholar.org/e57d/7927853180eff18bd89906ddf4ab8c5c31d4. pdf. Acesso em 6.Mai.2018.

TERRA, Márcia (2003). O behaviorismo em discussão. In http://www. unicamp.br/iel/site/alunos/publicacoes/textos/b00008.htm. Acesso em 6.Mai.2018.

TICKS, Luciane Kirchhof (2008). (Re)Construção de concepções, práticas pedagógicas e identidades por professoras de inglês pré e em serviço. (Tese - Doutorado) - Universidade Federal de Santa Maria, Centro de Artes e Letras, Programa de Pós-Graduação em Letras, RS.

VYGOTSKY, Lev Semyonovich (2001). A construção do pensamento e da linguagem. São Paulo: Martins Fontes.

Amanda Canterle Bochett é Mestre em Estudos Linguísticos pela UFSM. Doutoranda em Estudos Linguístico pela UFSM. Membro do grupo de pesquisa Linguagem no Contexto Social do Programa de Pós-Graduação em Letras da UFSM. Membro do Núcleo de Estudos em Língua Portuguesa - Nelp (UFSM).E-mail: amandacanterle@yahoo.com.br.

Jéssica Cantele de Freitas é Mestre em Estudos Linguísticos pela UFSM. Membro do Núcleo de Estudos em Língua Portuguesa - Nelp (UFSM). E-mail: jeh.cantele@hotmail.com. 
Maísa Helena Brum é Mestre em Estudos Linguísticos pela UFSM. Doutoranda em Estudos Linguísticos pela UFSM. Professora do Ensino Básico Técnico e Tecnológico do Instituto Federal do Rio Grande do Sul Campus Sertão. Membro do grupo de pesquisa Linguagem no Contexto Social do Programa de Pós-Graduação em Letras da UFSM. Membro do Laboratório de Pesquisa e Ensino de Leitura e Redação - LabLer (UFSM). E-mail: maisahbrum@gmail.com. 